\title{
Mentoring International Teaching Assistants: A Case Study of Improving Teaching Practices
}

\author{
Ekaterina Arshavskaya, PhD \\ Assistant Professor, Department of Languages, Philosophy, and \\ Communication Studies \\ Utah State University
}

While there exists a considerable body of research focusing on international teaching assistants' (ITAs') linguistic, sociocultural, and instructional challenges, less is known about the successful developmental trajectories of this group of international educators of American students. This research aims to fulfill this research gap using a case study approach (Yin, 2003). The study involved ITAs from STEM majors in six collaborative mentoring sessions prior and upon video recording of three lessons taught by the ITAs to undergraduate students. The mentoring sessions were designed to facilitate ITAs' reflections on their teaching with the use of structured protocols to help guide the discussions. All the collected data were analyzed using content analysis (Miles \& Huberman, 1994). The results highlight the incidents of professional growth exhibited by the participating ITAs during their actual teaching. This study also tracks the ITAs' reflections on teaching through the mediational dialogues

(Vygotsky, 1978) with the mentor. Finally, the paper discusses lessons learned through launching a mentoring project with a group of ITAs.

Despite the numerous efforts to support beginner teacher learning in the K12 context through mentoring, less attention has been paid to promoting teacher learning via collaboration with more expert educators at the university level, particularly with the use of video in teacher training (Williams \& Case, 2015). In order to facilitate this type of teacher development, a mentoring project involving videorecorded lessons was incorporated with a group of international teaching assistants (ITAs) at a U.S. university.

Over the past several years, U.S. higher education has employed an increasing number of international students to teach undergraduate courses in a variety of disciplines (Gorsuch, 2006; Jia \& Bergerson, 2008). With 1.13 million international students in the U.S. higher education (U.S. Immigration and Customs Enforcement, 2015), U.S.-born faculty, students, and other stakeholders have raised concerns pertaining to ITAs' English-language skills, teaching skills, and sensitivity to the cultural issues in the classroom (Gorsuch, 2006).

Recent research discussing ITAs' experiences in the U.S. classrooms has uncovered the many challenges that the ITAs experience as instructors in a new educational context, such as instructional, social, linguistic, and cultural challenges (Kuo, 2002). In response, solutions addressing the challenges that the ITAs face have been proposed to the ITAs' preparation programs (e.g., Gorsuch, 2017). Responding to the need to further facilitate ITAs' growth as teachers, a mentoring project was introduced at a medium-size public U.S. university involving a group of ITAs who were mentored with the use of video-recorded lessons during their semester of teaching STEM subjects to undergraduate students. The paper discusses the results of this mentoring project and the lessons learned when implementing it. 
While there exists a considerable body of research focusing on ITAs' professional development through established ITA preparation programs, less is known about ITAs' engagement (or lack of engagement) in professional development activities upon exiting these programs. Moreover, the benefits of continuing professional development are well-known in teacher education. Yet, less attention has been paid to both providing and investigating ITAs' opportunities to engage in continuing professional development upon exiting ITAs' preparation programs, which is due to the difficulties of launching and carrying out these pedagogical initiatives (e.g., Gorsuch, 2017). This research makes a unique contribution by addressing the need to further support ITAs' development of instructional expertise and by shedding light on the developmental trajectories of international educators of American students, as these unfold in a series of continuing professional development activities.

\section{Theoretical Foundations}

\section{Literature Review}

This study is grounded in Vygotskyan sociocultural perspective (Vygotsky, 1978). Vygotskyan sociocultural theory holds that all human cognitive development is mediated by human engagement in the social activities of a given society (Vygotsky, 1981). Vygotsky (1981) wrote that "all higher mental functions are internalized social relationships" (p. 164). In other words, human cognition develops through concrete social contexts and interactions among people.

During the activities of mentoring, novice teachers are engaged in actual teaching and also in teaching-related discussions with a more expert other (a mentor). During these discussions, novice teachers externalize their understanding of teaching and thus open their minds for social mediation from a mentor. The mentor, by externalizing more expert ways of thinking about teaching, makes them visible to a novice. Among the tools that mediate such interactions are lesson plans, supplementary materials, and other symbolic mediational means. As teachers gain greater instructional expertise, some of these tools may be less useful. For example, while beginning teachers oftentimes write detailed lesson plans, more experienced teachers prefer brief outlines or no lesson plans (Tasker, Davies, \& Johnson, 2010).

Another relevant concept is the zone of proximal development (ZPD). From a sociocultural theoretical perspective, the ZPD is defined as "an interaction during which, through mediation, an individual achieves more than she could have achieved if she had been working alone. During the ZPD, learning leads development" (Swain, Kinner, \& Steinman, 2011, p. 153). Ultimately, interactions within a learner's (in this case, a teacher's) ZPD may lead to the transformation of not only the learner (the teacher), but also of all other participants, the mediating tools, and the activity itself.

Mediation is "the process through which humans deploy culturally constructed artifacts, concepts, and activities to regulate...the material world or their own and each other's social and mental activity" (Lantolf \& Thorne, 2006, p. 79). In the context of education, the goal of mediation inheres in promoting learners' cognitive development. Moreover, within this framework, special attention is paid to the quality of mediation (Aljaafreh \& Lantolf, 1994). In the context of English teacher mentoring in South Korea, Ahn (2009) reports on the experiences of a mentor and a pair of pre- 
service teachers assigned to her. In Ahn's account, the pre-service teachers are initially willing to teach English in more communicative ways (e.g., through discussion, games); however, the mentor is more focused on accuracy, repetition, and structure in her teaching, which has a major impact on how the two pre-service teachers begin to think about and practice teaching. While the mentor's approach to teaching English can benefit students in terms of being able to pass a standardized English test, students exposed to this method of teaching English may not be able to develop their ability to communicate. As a result, many international students from Asia find it difficult to speak and to take a proactive role in college classrooms in an English-speaking environment (Sawir, 2005). Overall, Ahn's (2009) research shows the important role mentors play in constructing pre-service teachers' conceptions of good teaching and their actual teaching practices.

A sociocultural perspective also argues that with proper mediation, contradictory experiences (e.g., differences in opinions of the mentor and the novice) can promote development of all participants. For example, according to this perspective, after-class discussions, which may involve co-teachers (or, a mentor and a novice teacher) and students from a particular class, can serve as a place where perceived contradictions are articulated and participants can work collaboratively to find solutions to problems (Roth \& Tobin, 2004).

ITAs' experiences in the U.S. classrooms. ITAs, as new instructors in international contexts, often experience challenges relating to classroom management, content instruction, culture, societal norms, and language. Regarding classroom management issues, ITAs admit that a lack of information about the U.S. grading and testing system often makes them experience lack of control (Lin \& Yi, 1997). Many ITAs also share the instructional challenges that they face in U.S. classrooms such as feeling frustrated over having to change their teaching style (Torkelson, 1992). In fact, Kim (2014) showed that many ITAs continue to practice a teacher-centered, rather than a student-centered, approach to teaching due to respective pedagogical beliefs. In relation to cultural challenges, ITAs admit feeling uncomfortable by the expectation that they call their professors by their first names (Bresnahan \& Cai, 2000). In addition, many ITAs find it difficult to adapt to the more informal relationship characteristic of the U.S. students and faculty (Kuo, 2002). Regarding social challenges, some ITAs report that they find it difficult to make friends with Americans, as the ITAs may prioritize their obligations to the home communities and, therefore, have less time to develop relationships with U.S. peers (Smith, 1993). Lastly, in relation to linguistic challenges, many ITAs find it difficult to communicate effectively with their U.S. students both inside and outside the classroom (Li, Mazer, \& Ju, 2011). More specifically, research shows that while many ITAs master discipline discourse, they may not be proficient in conversational English, which makes it difficult for them to communicate during office hours (Chiang, 2016).

In order to address the various challenges that ITAs encounter, ITA preparation programs have employed a number of different approaches. For example, to address social and cultural challenges, a buddy program for ITAs, which involves pairing an ITA and a U.S. undergraduate student for the duration of one academic semester with the purpose of fostering informal social interactions, has been successful at the Michigan State University (Altinsel \& Rittenberg, 1996). Staples, Kang, and 
Wittner (2014) found that informal interactions between U.S. undergraduate students and ITAs positively impact undergraduate students' perceptions of ITAs' comprehensibility and teaching ability. In a similar vein, Kang, Rubin, and Lindemann (2015) reported that U.S. undergraduate students rated ITAs higher in terms of instructional competence and comprehensibility upon engaging in a series of cooperative problem-solving exercises. In addition, some U.S. universities engage U.S. undergraduate students in an intercultural training course (Ross, 2007) with the goal of fostering a sense of openness toward other cultures on the part of this group of students. In order to help ITAs improve their ability to clearly communicate course content to their U.S. students, researchers encourage ITAs to use a dialogic approach during class meetings (Li et al., 2011). In particular, while an ITA's self-disclosure of language inadequacy in the classroom has negative effects on students' perceptions of the ITA's clarity as an instructor, the students perceive the ITA's attempts to resolve his/her language inadequacy in the classroom through a dialogue with them as a genuine effort to achieve mutual understanding, with the result that the ITA's overall instructional credibility is supported. Lastly, some ITAs' preparation programs establish collaborative relationships with the ITAs' discipline departments and offer discipline-specific practica (Gorsuch, 2006, 2017). Despite many difficulties associated with launching such a course, the positive effects on ITAs' discourse intonation and teaching strategies make such endeavors worthwhile to implement (Gorsuch, 2017).

To summarize, research shows that ITAs oftentimes experience certain instructional, socio-cultural, and linguistic challenges while teaching in the U.S., prompting ITA- preparation programs to extend the support offered to this group of international educators by organizing informal encounters with U.S. undergraduate students, discipline-specific mentoring, and others.

Facilitating teacher development. One of the many ways to facilitate teacher development of instructional expertise lies in creating mediational spaces (e.g., teaching journals, mentoring sessions) wherein teachers can reflect on their teaching practices and consider alternative modes of engagement in the classroom. Verity (2001) reports on her own developmental journey as a language teacher in a new cultural environment (Japan) and her ability to mediate herself towards new, more effective modes of engagement in the classroom through externalizing her thoughts and feelings in a teaching journal. In another study, Tasker et al. (2010) demonstrate how an experienced language teacher was able to clarify his concerns related to teaching and develop an idealized conception of a classroom with a commitment to action through dialogues with a colleague. In this case, the colleague oftentimes served as a "sounding board" who was able to listen and ask probing questions in order to prompt the teacher to formulate his own solutions to the instructional problems he encountered.

Another way to promote teacher reflection involves the use of videorecorded lessons taught by a novice and a subsequent co-reflection on these videos in collaboration with a more expert other. For example, Golombek (2011) showed how a teacher educator shifted her mediation from implicit to more explicit in response to a pre-service teacher's needs during their interaction in regard to the video recording of a class the latter had taught. Through analysis of the transcripts of her conversation with a language pre-service teacher, Golombek (2011) explored the quality and character of this interaction. In particular, she demonstrated how the teacher 
educator's and the pre-service teacher's engagement in this dialogic activity had enabled the former to understand the latter's thinking and modify mediation accordingly. In this interaction, the teacher educator fostered the novice's ability to think about why she had made certain choices in the classroom. In other words, the teacher educator engaged the novice in reasoning teaching (Johnson, 1999) and articulating alternative instructional solutions to various classroom situations.

Less is known about the impact of video on the development of ITAs' professional expertise (Williams \& Case, 2015). Also, the majority of previous research focuses on ITAs' teaching in somewhat artificial settings, i.e., simulated teaching sessions (LeGros \& Faez, 2012), rather than in a real classroom. Following a recent call to use videos as a basis for ITAs' training (Williams \& Case, 2015), this study investigates the impact of video on ITAs' developmental trajectories. Unlike previous research (e.g., Williams \& Case, 2015), this study relies on several teaching and reflection sessions with ITAs, which allows for a more in-depth investigation of successful developmental trajectories of the participating students.

Summary. Overall, research on teacher learning suggests various ways to promote teacher development of professional expertise. One of the ways is to employ video-recorded lessons and after-lesson reflection sessions facilitated by a mentor or a colleague. However, research on the use of video in ITAs' training is only beginning to emerge (Williams \& Case, 2015). Following this emergent body of research, this study involved ITAs in a mentoring project with the use of video implemented at a U.S. university upon their completion of the ITAs preparation program with the goal of further supporting ITAs' development of teaching expertise.

\section{Research Design}

\section{Methodology}

The project involved two ITAs participating in mentoring encompassing reflection sessions before and after each of their three lessons taught to U.S. undergraduate students. The data collected included: (1) six video-recorded mentoring sessions with each of the participants, (2) three video-recorded lessons taught by each of the participating ITAs, and (3) short reflection papers where the participants reflected on their overall experience in the project. The protocols developed for this project and used to guide mentoring sessions are presented in Appendix A.

Also, for triangulation purposes, the research utilizes data from a focus-group discussion. All the ITAs enrolled in the ITA preparation course in a subsequent academic semester at the same university were asked via email to participate in a focusgroup discussion. Several students replied. A moderator facilitated the focus group, which was conducted in a university classroom. The focus group session lasted approximately 1 hour. The researcher attended the session but did not participate. At the end of the session, which was audio-recorded for transcription purposes, the participants were asked to complete a questionnaire (see Appendix B).

Responding to the need to support ITAs' development of instructional expertise, the paper's primary goal is to examine the developmental trajectories of two ITAs in the continuing professional development context at a U.S. university. This qualitative research study pursued the following research question: How do the 
mentoring sessions with the use of video-recorded classes taught by ITAs mediate their development of teaching expertise?

\section{Population and Sample Selection}

The study involved two ITAs upon their completion of the ITAs' preparation course at a U.S. university in a mentoring project with the use of video and reflection sessions. In this study, the names of the two focal participants were replaced by pseudonyms to protect their privacy.

One of the participants, Tao (from China), pursued a doctoral degree program majoring in engineering education at the time of the data collection. Prior to the start of the project, he taught for one year overall both in his home country and in the U.S., which involved a number of introductory courses for engineering students. The other participant, Arash (from Jordan), also a doctoral student, as well majored in engineering education. He had taught in his home country for five years prior to pursuing a doctoral degree program in the U.S. His prior teaching experience involved a number of college-level courses such as computer-assisted graphics, engineering economics, dynamics, and statics.

Additionally, several ITAs agreed to participate in a focus-group discussion related to this group of students' attitudes toward continuing professional development opportunities overall. This data was collected to inform this study as well as to serve for triangulation purposes.

\section{Data Collection}

The ITAs were recruited upon their completion of the ITAs' preparation course offered at a southwestern public U.S. university. Out of a cohort of 45 students, only two students who majored in engineering education volunteered to participate in the project. At the beginning of the project, the participants filled out a short background questionnaire (see Appendix C).

In addition, in a subsequent academic semester, several ITAs were recruited via an email to participate in a focus-group discussion.

\section{Data Analysis}

The data analysis focused on the contents of the ITAs' interactions with the mentor (also, the researcher and the author of this article) and their perceptions of the mentoring experience with the use of grounded theory (Glaser \& Strauss, 1967). The data sources were transcribed and then read and re-read by the researcher multiple times in order to identify the most salient themes that emerged in the participants' classroom interactions, reflection sessions with the mentor, and final (after-project) reflection papers. The data from the focus-group discussion was approached in the same manner.

\section{Results}

The study shows that the mentoring approach applied to both ITAs allowed them to improve their teaching as well as to exhibit a certain extent of teacher reflection 
during one-on-one mentoring sessions and achieve a greater level of student engagement in the classroom towards the end of the semester.

Following conventional qualitative methods, the researcher identified two themes as the most salient in the data of the participating teachers, Tao and Arash. Each participant focused on (1) personal limitations as a teacher and possible solutions and (2) strategies that ensured their success in the classroom.

From the start of the project, both ITAs were aware of certain shortcomings they had as instructors. Thus, while Tao admitted that he sometimes experienced some miscommunication with English native speakers due to his accent, Arash was aware of his tendency to talk too fast, which posed a problem in his interacting with students who could not always follow his fast explanations during instruction. Such awareness constitutes the first step towards developing as a teacher.

At the same time, the two ITAs also exhibited many other qualities that helped them to gradually become more successful in the classroom. First, both the ITAs were collaborating with their advisors and students in order to improve their teaching. Second, they were particularly attentive to the levels of student engagement in their classes and implemented several instructional strategies to increase student participation, as the project unfolded. Third, they were both aware of some institutional constraints and were able to reflect on them. Lastly, both the ITAs were aware of the importance of a positive student-teacher relationship and found ways to improve it. In addition, one of the participants (Arash) demonstrated a certain extent of cultural sensitivity as a teacher and reflected on the ways to become more successful in this new cultural environment in the future.

In the paragraphs that follow, the main findings are explained in greater detail with the use of relevant data excerpts.

\section{Mentor as a "Sounding Board" in Mediational Dialogues with ITAs}

As mentioned earlier, both Tao and Arash were aware of certain personal limitations as instructors and on this basis, were able to externalize concrete professional goals to achieve by the end of the project. Thus, Arash externalized his concern about talking too fast during the first mentoring session (prior to teaching his first class) after being prompted by the mentor.

\section{Excerpt 1 .}

Mentor: So, for your first lesson, can you choose any topic...or anything we can focus on?...There are some examples here, like student motivation, what kinds of questions you use to engage them. Or, anything about your presentation.

Arash: Yeah, ok. So, well, probably, talking too fast. I usually talk too fast. Just the rate of speech. (Mentoring session 1)

In the excerpt above, the mentor prompts the ITA to identify a certain aspect of his teaching that seems problematic to the latter. While the mentor does offer some topics, Arash chooses a topic of his own. Here and hereafter, the mentor mostly serves as a "sounding board" prompting the ITAs' reflection on teaching during their mediational dialogues, which signals a certain extent of teacher autonomy on the part of the participating ITAs. 
While at the end of the semester Arash admits that his rate of speech is still fast, he also acknowledges that he was able to slightly overcome this issue by slowing down and asking more questions during the classes he had taught during the project. In fact, whereas he finished his first lesson twenty minutes earlier, he was able to finish two other classes he had taught as part of the mentoring project on time.

Excerpt 2.

Arash: I've learned that I need more preparation and to practice a bit more in order to have a better grasp on time and not take more than I should or less than I should which is what was happening during those lectures. I took about $70 \%$ of the class time, and while students like getting off early, the additional time could have been used to reiterate or explain at a slower pace or for the sake of a more interactive class. (Final reflection paper)

In a similar vein, during a mentoring session at the start of the semester, Tao admitted that he had talked too fast during his first lesson.

Excerpt 3.

Mentor: So, what went well and why?

Tao: I think everything went well since I felt most students understood what I taught. The only thing is that I speak too fast. Yeah, that is part of my classroom management skills. I still need to improve that part. (Mentoring session 2)

In fact, Tao finished his first lesson ten minutes earlier. To compensate for this, Tao planned to implement the following strategies in his subsequent teaching: slowing down and using wait time.

Excerpt 4 .

Mentor: So, maybe you can slow down next time?

Tao: Yeah, slow down and sometimes I'm just not very patient to wait for five minutes for them, but I should do that, give them time, more time to them. (Mentoring session 2)

In the excerpt above, the mentor suggests a possible solution to the problem externalized by the ITA (slowing down), and the ITA continues the discussion by offering his own strategy to address the issue (using wait time). And indeed, Tao was able to use better classroom management skills during the second and third lessons he had taught as part of the project. Furthermore, in his final reflection paper, Tao identified better classroom management skills as a major "gain" from his participating in the project, as the following excerpt illustrates.

Excerpt 5 .

Tao: At the first lecture in a real classroom facing about 100 students, I was a little bit nervous, which I noticed in the video. Under the pressure, I spoke pretty fast, also confirmed from the students' feedback, so the consequence is I finished the lecture content 10 minutes early than expected. So, next time I tried my best to calm down and slow my speaking and at the same time prepared more content for the students, which gave me flexibility to manage the lecture time. (Final reflection paper) 
Previous research shows that clear goal setting constitutes the first step to success (Smith, 1993), particularly as it relates to teacher professional development. In the interactions above, both the ITAs were able to identify an instructional concern and frame it as a goal to achieve. In her turn, the mentor served as a "sounding board" who asked probing questions and mainly facilitated a space to reflect on one's teaching rather than provide solutions. While working within the participants' ZPD, the mentor was not necessitated to use a more directive style of mentoring. From a sociocultural perspective, it shows the necessity to dynamically scaffold students' (in this case, ITAs') learning while using less explicit mediation first on the teacher's or mentor's part (Aljaafreh \& Lantolf, 1994; Lantolf \& Thorne, 2006).

\section{Mediational Tools that Ensured ITAs’ Gradual Success in the Classroom}

As mentioned earlier, both the ITAs utilized a number of strategies (or, mediational tools) that ensured their success both in the classroom and during the mentoring sessions. The excerpts below illustrate this claim.

First of all, both the ITAs were collaborating with their advisors and students in order to improve their teaching. For example, both Tao and Arash sought feedback from their advisors upon their teaching by sharing video recordings of each lesson and discussing their teaching. In addition, they interacted informally with their students during office hours and laboratory sessions in order to receive another perspective on their teaching. Moreover, they were both interested in exploring these additional perspectives in greater depth in the future, as the following excerpt demonstrates.

Excerpt 6.

Arash: Sending brief questionnaires to the advisor of the participating ITA as well as to the students attending the class to see the perspective of an expert in the field as well as the recipients of the lecture whose feedback is extremely important to improvement. I have tried to get feedback from students, but didn't get much, but I am sure that anonymous surveys or questionnaires would yield more honest input. (Final reflection paper)

As the excerpt above shows, while Arash was able to utilize his advisor's and students' feedback as a helpful mediational tool, he also externalized a desire to use it at a greater depth in his subsequent teaching practice. The latter was not feasible during the project due to the fact that ITAs were not instructors of record, and therefore, the institutional student evaluations of their teaching were not available.

Second, both the ITAs were particularly attentive to the levels of student engagement in their classes and implemented several instructional strategies to increase student participation, as the project unfolded. First, both Tao and Arash incorporated more questions to the students during their second and third lessons, as compared to the first lessons they taught. They also increased their wait time to let students process the information and develop solutions. In addition, both the ITAs were aware of the importance of a positive student-teacher relationship and found ways to improve it. For example, Tao arrived earlier to the second lesson he had taught during the project and engaged students in some small talk in order to establish a more positive atmosphere in the classroom. 
Excerpt 7.

Tao: Then, this time I tried to involve the students a little more. This time I arrived a little bit earlier and I just talked to some students there. I think that let them warm up. So, they are not afraid to ask questions....So, when we started the class and I asked them a content question, these guys just answered this. I think I should involve more students before the class, talking to them, walking around. There was more participation this time. (Mentoring session 4)

Third, both the ITAs were aware of certain institutional constraints and were able to reflect on them. For example, Tao admitted that the curriculum was not as flexible as to allow him to explain some of the problems in greater detail in the class. In the future, if he has a full control over course schedule and assignments, he would prefer to make it more flexible. Also, Arash admitted that the institutional constraints did not allow him to make his presentation more interactive, i.e., the students could not directly engage with the software he was using during instruction due to a limited number of computers. Instead, the students had to wait till the laboratory time or to try it at home by themselves.

Lastly, one of the participants (Arash) demonstrated a certain extent of cultural sensitivity as a teacher and reflected on the ways to become more successful in a new cultural environment in the future. Thus, he admitted that in the U.S., students were more reluctant to ask questions than in his home country. Also, he was interested in finding ways to make his lesson beginnings more engaging by learning more about U.S. humor, as the excerpt below shows.

Excerpt 8 .

Arash: My intros...to lectures could also use some work as I start the class suddenly and end it as abruptly as I had started it, while I do a good job in the middle, I think I need some transition phase before the class starts and at the end of it. I used to do that in Jordan, but still can't do that here as I need some time to adjust to the environment and know how to open with an appropriate joke or small talk or something to get the students to notice class has begun. It is definitely something I used to do, and should get back into the habit of doing again once I get more comfortable to what is appropriate and what isn't in this culture. (Final reflection paper)

Overall, while some of the mediational tools the ITAs employed helped make their instruction more successful by, for example, increasing levels of student engagement, some of the mediational tools were not available to the ITAs during the course of this project (e.g., anonymous feedback from students), a limitation that can be addressed in subsequent studies. Also, both the ITAs were aware of certain institutional constraints, which as well could not be addressed within the context of this research (e.g., a limited number of computers for students).

Finally, in order to gain insights into ITAs' motivation (or lack of thereof) to participate in continuing professional development, focus-group data were collected in a subsequent semester. The focus-group data shows that ITAs would gladly participate in professional development activities upon completing the university training program. Out of a cohort of 35 ITAs in a subsequent semester, all of them 
showed potential interest in this project. For example, one ITA noted that "he would participate in additional mentoring since he wants to be a better teacher". Another ITA admitted that this "seems as a great opportunity" and that she "would gladly participate in the following semester as she gains "a bit more experience". However, not all the ITAs are able to receive teaching assistantships (TAs). Furthermore, even if they receive TAs, they are mainly assigned to grade student work rather than hold lab sessions or even give classes. This institutional constraint appears to be a key factor to impact ITAs' actual willingness to engage in continuing professional development.

\section{Discussion}

This study has a range of implications for future research, particularly in the context of ITAs' training. First, the study confirms an earlier research finding (Poehner, 2011; Tasker et al., 2010) according to which interactions with colleagues and mentoring can be a significant tool in mediating teachers' development of instructional expertise. In this study, both the ITAs were able to externalize certain concerns relating to a number of aspects of their teaching (e.g., student participation) and formulate and even implement some of the solutions. For example, after externalizing a desire to engage in new modes of engagement in the classroom, Tao was able to establish a closer and more positive student-teacher relationship by holding some informal interactions with his students prior to his class.

At the same time, given the participating ITAs' prior experience in teaching and corresponding background (i.e., majoring in engineering education), it is possible that solely the mediational spaces created through the project were of key importance to the ITAs' development. Similarly to Verity (2001), the two teachers were able to selfmediate themselves towards embracing new ways of teaching. Here, the concept of ZPD seems particularly relevant, i.e., while some new teachers may require a more direct style of mentoring, the participating instructors' ZPD allowed the mentor to mainly serve as a "sounding board." Consequently, one of the practical implications of this research lies in its highlighting the importance of providing beginning teachers (in this case, ITAs) opportunities to "see" their teaching (video-recorded lessons) and to have spaces to reflect on what they "saw." While the major thrust of existing research on ITAs does not utilize videos (Williams \& Case, 2015), this study shows its potential benefits for ITAs' development of professional expertise overall.

In addition, the study confirms Vygotskian sociocultural theory (Vygotsky, 1978) by showing that through mediational dialogues, learners (in this case, teachers) can develop further by, for example, externalizing their concerns and formulating certain solutions to implement in subsequent lessons. In particular, during the mediational dialogues, the mentor's working within the participants' ZPD prompted the ITAs to formulate instructional concerns and to suggest solutions. Among other mediational tools that the ITAs found particularly useful were the interactions with their advisors and students, using wait time, and incorporating more questions to make their instruction more interactive. At the same time, some of the mediational tools in which the ITAs were interested (e.g., anonymous feedback from students) were not available during the project and could, therefore, be implemented in future research. 
Next, the study findings show that both the ITAs were able to demonstrate a certain level of autonomy and reflection during the provided mentoring sessions and to exhibit some instructional success in the classroom. This success can be due to the fact that both the ITAs had taught prior to the start of the project. In this way, they were somewhat familiar with the instructional context and student population. Also, both the ITAs were engineering education majors, which can account for their professional interest in becoming a better teacher. On this basis, the article challenges certain biases that educators may hold of this group of students (i.e., their lack of success as instructors in a new educational context), which may prevent us from tailoring our instruction to better meet these students' needs. A similar claim has been made with regard to writing instruction to bilingual students (Riazantseva, 2012). While it seems impossible to generalize the findings of this article to larger populations of students, this article represents some of these voices. Moreover, unlike previous research (Williams \& Case, 2015), this study utilizes several teaching and reflection sessions with ITAs supported by the use of video. This resulted in a more in-depth investigation illustrating successful developmental trajectories of the participating ITAs. Also, while Williams and Case (2015) report that the participating ITAs through discussing the videos of their teaching expressed a commitment to enhance their instructional practices in various ways, this study showed the complex ways in which the ITAs' teaching practices actually developed overtime. For example, both Arash and Tao were able to increase student participation as the project unfolded; however, the cultural component of instruction remained an issue (i.e., Arash's desire to learn more about U.S. humor in the context of a college classroom).

The study findings also agree with Vygotskian ideas about the nature of transformative experiences in the context of education. Within this framework, it is suggested that through mediational experiences all the participants become transformed. In this study, both participating ITAs re-framed certain aspects of their teaching whereby Arash and Tao developed better classroom management skills and learned to make their teaching more interactive. The sociocultural theory, therefore, represents a useful analytical tool that researchers can draw on in examining teachers' transformative experiences in teacher preparation programs more generally.

Finally, the paper raises questions relating to the ITAs' motivation to engage in continuing professional development. Out of a cohort of 45 students, only two ITAs majoring in engineering education agreed to participate in this research. Yet, during a subsequent academic semester, all 35 enrolled ITAs' expressed potential interest in participating in continuing professional development. This discrepancy may be due to certain institutional limitations discussed earlier (i.e., many ITAs are assigned to grade student work rather than actually teach). However, the limited sample does not allow to make major generalizations at this point and can be addressed in further research.

\section{Conclusion}

While the use of mentoring to support teacher learning continues to grow in the U.S. and worldwide, particularly in K-12 contexts, more research is needed to understand the affordances and constraints of the learning environments at the 
university level, particularly with the use of video. This study revealed that mentoring allowed the participants to externalize their thoughts and feelings about their teaching and implement some of the strategies to enhance it. The mentoring sessions allowed ITAs to realize their limitations (e.g., talking too fast) and the ways to overcome these limitations (e.g., developing awareness of cultural differences in the classroom, having ...mentoring allowed the willingness to collaborate with students and advisors, and others). Such mentoring endeavors can also help teachers gain confidence and exchange teaching strategies. In the future, this process could involve an extended use of the mediational tools that the ITAs found particularly effective (e.g., anonymous

feedback from their students). Furthermore, given participants to externalize their thoughts and feelings about their teaching and implement some of the strategies to enhance it. that both the ITAs were relatively experienced teachers majoring in engineering education, future investigations could involve a larger and perhaps more diverse pool of participants sufficient to draw general inferences. Lastly, surveying the ITAs regarding motivational factors in future studies seems a worthwhile endeavor. In particular, it would be interesting to explore whether ITAs will rely on informal methods for improving teaching (e.g., peer interactions) in the absence of a formal mentoring program.

\section{References}

Ahn, K. (2009). Learning to teach within the curriculum reform context: A sociocultural perspective on English student teachers' practicum experience in Korea. (Unpublished doctoral dissertation). Pennsylvania State University, University Park.

Aljaafreh, A., \& Lantolf, J. (1994). Negative feedback as regulation and second language learning in the Zone of Proximal Development. The Modern Language Journal, 78(4), 465-483.

Altinsel, Z., \& Rittenberg, W. (1996). Cultural support for international TAs: An undergraduate buddy program. Paper presented at the annual meeting of the Teachers of English to Speakers of Other Languages, Chicago, IL (ERIC Document Reproduction Service No. ED 407918).
Bresnahan, M. J., \& Cai, D.H. (2000). From the other side of the desk: Conversations with international students about teaching in the U.S. Communication Quarterly, 48(2), 65-75.

Chiang, S.-Y. (2016). "Is this what you're talking about?": Identity negotiation in international teaching assistants' instructional interactions with U.S. college students. Journal of Language, Identity and Education, 15(2), 114-128. doi: 10.1080/15348458.2016.1137726

Glaser, B. G., \& Strauss, A. L. (1967). The discovery of grounded theory: Strategies for qualitative research. New York, NY: Aldine de Gruyter. 
Golombek, P. R. (2011). Dynamic assessment in teacher education: Using dialogic video protocols to intervene in teacher thinking and activity. In: K. E. Johnson \& P. R. Golombek (Eds.) Research on second language teacher education: A sociocultural perspective on professional development (pp. 121-135). New York, NY: Routledge.

Gorsuch, G. J. (2006). Discipline-specific practica for international teaching assistants. English for Specific Purposes, 25(1), 90-108.

Gorsuch, G. (2017). An evaluation of a teaching practicum course for international teaching assistants. Unpublished manuscript. doi: 10.13140/RG.2.2.17897.29283

Jia, C. J., \& Bergerson, A. A. (2008). Understanding the international teaching assistant training program: A case study at a northwestern research university. International Education, 37(2), 77-98.

Johnson, K. E. (1999). Understanding language teaching: Reasoning in action. Boston, MA: Heinle and Heinle.

Poehner, P. (2011). Teacher learning through critical friends group: Recontextualizing professional development in a K-5 school. In: K. E. Johnson \& P. R. Golombek (Eds.), Research on second language teacher education: A sociocultural perspective on professional development (pp. 189-203). New York, NY: Routledge.
Riazantseva, A. (2012). "I ain't changing anything": A case-study of successful generation 1.5 immigrant college students' writing. Journal of English for Academic Purposes, 11, 184-193. doi: 10.1016/j.jeap.2012.04.007

Ross, C. (2007, March). Redirecting the flow of university intercultural responsibility. Paper presented at the meeting of the $41^{\text {st }}$ Annual Teaching English to Speakers of Other Languages Convention, Seattle, WA.

Roth, W., \& Tobin, K. (2004). Coteaching: From praxis to theory. Teachers and Teaching: Theory and Practice, 10(2), 161-179.

Sawir, E. (2005). Language difficulties of international students in Australia: The effects of prior learning experience. International Education Journal, 6(5), 567580 .

Smith, K. S. (1993). A case study on the successful development of an international teaching assistant. Innovative Higher Education, 17(3), 149163.

Staples, S., Kang, O., \& Wittner, E. (2014). Considering interlocutors in university discourse communities: Impacting U.S. undergraduate students' perceptions of ITAs through a structured contact program. English for Specific Purposes, 35, 54-65.

Swain, M., Kinnear, P., \& Steinman, L. (2011). Sociocultural theory in second language learning: An introduction through narratives. Bristol: Multilingual matters. 
Tasker, T., Davies, T., \& Johnson, K. (2010). A sociocultural analysis of teacher talk in inquiry-based professional development. Language Learning Research, 14(2), 129-140.

doi: 1177/1362168809353871

Torkelson, K. (1992). Using imagination to encourage ITAs to take risks. Paper presented at the annual meeting of the Teachers of English to Speakers of Other Languages, Vancouver, British Columbia, Canada (ERIC Document Reproduction Service No. ED 349 898).

Trebing, D. (2007). International teaching assistants' attitudes toward teaching and understanding of U.S. American undergraduate students. (Unpublished doctoral dissertation). Southern Illinois University, Carbondale, Illinois.

U.S. Immigration and Customs Enforcement. (2015, March 25). SEVP releases 2015 international student data, launches interactive mapping tool. ICE Newsroom. Retrieved from https://www.ice.gov/news/releases/sev p-releases 2015-international-studentdatalaunches-interactive-mapping-tool
Verity, D. P. (2001). Side effects: The strategic development of professional satisfaction. In: J. P. Lantolf (Ed.) Sociocultural Theory and Second Language Learning (pp. 179-197). Oxford: OUP.

Vygotsky, L. S. (1978). Mind in society. Cambridge, MA: Harvard University Press.

Vygotsky, L. S. (1981). The instrumental method in psychology. In: J. V. Wertsch, (Ed.), The concept of activity in Soviet psychology (pp. 134-144). Armonk, NY: M.E. Sharpe.

Williams, G. M., \& Case, R. E. (2015) Tale of the tape: International teaching assistant noticing during videotaped classroom observations. Journal of International Students, 5(4), 434-446.

Yin, R. K. (2003). Case study research: Design and methods (3 ${ }^{\text {rd }}$ ed.). Thousand Oaks, CA: Sage. 


\section{Appendices \\ Appendix $\mathbf{A}^{1}$}

Mentoring Session Protocols

General Comments

1. How do you feel about the lesson overall?

2. What went well? Why?

3. What did not go well? Why (not)?

4. If you teach this lesson again, what aspects would you change and why (not)?

Students

5. How engaged were the students? How do you know? How could you increase student participation if you taught this lesson again?

6. Were any parts of the lesson challenging to the students? If yes, how did you address these challenges? If you teach this lesson again, what would you do differently in terms of facilitating student understanding?

Teacher

7. How was the rate of your speech? How about pronunciation, grammar, and vocabulary?

8. How clear were your explanations? If you teach this lesson again, what would you do differently in terms of making your explanations more clear?

9. How effective were the visual aids you used, if any?

Classroom Facilities

10. What about the classroom facilities? If you teach this lesson again, what aspects of the classroom facilities would you change and why (not)?

\section{Appendix B}

Focus-Group Questionnaire

1. How did you feel about the ITAs' training course in terms of preparing you to teach U.S. students at this university (e.g., sufficient/insufficient, etc.)?

2. What topics and/or activities discussed in the course were necessary and, on the opposite, not presented in depth or even omitted?

3. If you are given your TA-ship for this academic semester, would you allow the ITA instructor to record and subsequently analyze and coreflect on three of your teaching sessions for the purpose of continuing professional development? Why (not)?

${ }^{1}$ Based on Morford, M. (October 12, 2006) and Lesson Reflection Checklist (n.d.). 


\section{Appendix C}

Background Questionnaire

Personal Information

1. Full name:

2. Nationality:

3. Native language(s):

4. Knowledge of other languages:

5. Major:

6. Degree sought:

Teaching Experience

7. Please specify the department you have worked for/are working for:

a. Which courses have you taught?

b. What are/were your specific responsibilities?

c. How long have you been teaching?

8. Did you have teaching experience before coming to the U.S.? If so, please describe.

a. Where did you teach (country, institution)?

b. How long did you teach (time, semesters)?

c. Please describe your students (gender, backgrounds, etc.).

Proficiency in English

9. How do you feel about communicating in English (e.g., confident, nervous, fluent)?

10. How do you feel about your proficiency in English? Please be specific. Evaluate your writing, reading, speaking, and listening skills. Mentoring Project

11. What professional goals do you pursue by participating in this project (e.g., improve classroom management skills, develop a more confident teacher persona, collect data on student off-task behaviors and implement measures to address these behaviors, etc.)?

12. How do you feel about discussing your lessons and receiving feedback on your teaching? What should I consider when discussing your teaching sessions with you? (Adapted from Trebing, 2007)

Ekaterina Arshavskaya has worked as an EFL/ESL instructor for over 11 years. Her previous work assignment took place at Penn State where she taught academic writing courses to both undergraduate and graduate international students as well as worked with the International Teaching Assistants (the ITAs). Currently, she is an assistant professor of English as a Second Language (ESL) at the Utah State University (Logan, UT). Her teaching and research interests include second language (L2) writing and ITA program development.

Dr. Arshavskaya is a member of the American Association of Applied Linguistics (AAAL) and Teaching English to Speakers of Other Languages (TESOL). 